\title{
Traditional Knowledge on Genetic Resources: Safeguarding the Cultural Sustenance of Indigenous Communities
}

\author{
Wan Izatul Asma Wan Talaat ${ }^{1,3}$, Norhayati Mohd Tahir ${ }^{2,3} \&$ Mohd Lokman Husain ${ }^{3}$ \\ ${ }^{1}$ Faculty of Management \& Economics, Universiti Malaysia Terengganu, Kuala Terengganu, Malaysia \\ ${ }^{2}$ Faculty of Science \& Technology, Universiti Malaysia Terengganu, Kuala Terengganu, Malaysia \\ ${ }^{3}$ Institute of Oceanography, Universiti Malaysia Terengganu, Kuala Terengganu, Malaysia \\ Correspondence: Wan Izatul Asma Wan Talaat, Faculty of Management \& Economics, Universiti Malaysia \\ Terengganu, 21030 Kuala Terengganu, Malaysia. Tel: 60-9-668-4273. E-mail: wia@umt.edu.my
}

$\begin{array}{lrr}\text { Received: February 1, } 2012 & \text { Accepted: March 6, } 2012 & \text { Published: June 1, } 2012 \\ \text { doi:10.5539/ass.v8n7p184 } & \text { URL: http://dx.doi.org/10.5539/ass.v8n7p184 }\end{array}$

This research is funded by the Malaysian Ministry of Higher Education

\begin{abstract}
Traditional knowledge, generally defined as the long-standing traditions and practices of certain regional, indigenous, or local communities, constitutes a cumulative body of knowledge, know-how, practices, and representations maintained and developed by peoples with extended histories of interaction with the natural environment. Recognition, protection and enforcement of the rights of indigenous communities to have continued access to biological genetic resources is quite related to the principle of sustainable and use of biological diversity crucial not only for the continued sustenance of their culture but also to protect their knowledge, acquired over thousands of years of experimentation and experience, about the uses biological resources can be put to particularly in medicinal and pharmaceutical preparations. The signing of the Convention on Biological Diversity (CBD) in 1992 has brought international intention to intellectual property laws to preserve, protect and promote their traditional knowledge. CBD recognises the value of traditional knowledge in protecting species, ecosystems and landscapes, which are inextricably associated to the sustainable conservation and use of natural resources. On the other hand, the subsequent adoption of the World Trade Organization (WTO) Agreement on Trade-Related Aspects of Intellectual Property Rights (TRIPS) in 1994 could be interpreted to contradict the agreements made under the CBD. This paper highlights the efforts to protect traditional knowledge in the midst of the dichotomy between CBD and TRIPS.
\end{abstract}

Keywords: associated traditional knowledge, indigenous communities, genetic resources, cultural sustenance, CBD, TRIPS

\section{Introduction}

Traditional knowledge is generally defined as the long-standing traditions and practices of certain regional, indigenous, or local communities encompassing the wisdom, knowledge, and teachings of these communities. It constitutes a cumulative body of knowledge, know-how, practices, and representations maintained and developed by peoples with extended histories of interaction with the natural environment (Feng Shui Times, 2003). Considered as an asset, it focuses on the use of knowledge such as traditional technical know-how, or traditional ecological, scientific or medical knowledge. The Secretariat of the Permanent Forum on Indigenous Issues (2005) defines traditional knowledge as,

“...developed from experience gained over the centuries and adapted to the local culture and environment, and transmitted orally from generation to generation. It tends to be collectively owned and takes the form of stories, songs, artistic expressions, proverbs, cultural events, beliefs, rituals, community laws, languages, agricultural practices, including the development of plant species and animal breeds, traditional know-how relating to architecture, textile-making and handicraft-making, fishery, health and forestry management." 
Traditional knowledge basically refers to the knowledge, innovations and practices of the indigenous and local communities globally. It is transmitted orally from generation to generation and developed from experience gained over the centuries and adapted to the local culture and environment. It is collectively owned and ranges from stories, songs, folklore, proverbs, cultural values, beliefs, rituals, community laws, local language, to agricultural practices, which include the development of plant species and animal breeds. Traditional knowledge is primarily of a practical nature, mainly in agriculture, fisheries, health, horticulture, and forestry. Knowing what it contains and how it is acquired and held is fundamental to being able to make good use of the knowledge and to encourage all parties to be aware of the added value its use will bring (Alaska Native Science Commission, 2006).

The signing of the Convention on Biological Diversity (CBD) in 1992 has brought international intention to intellectual property laws to preserve, protect and promote their traditional knowledge. The CBD entered into force in December of 1993 with the first meeting of the Conference of the Parties (COP-1) in November 1994. CBD recognises the value of traditional knowledge in protecting species, ecosystems and landscapes, which are inextricably associated to the sustainable conservation and use of natural resources. The subsequent adoption of the World Trade Organization (WTO) Agreement on Trade-Related Aspects of Intellectual Property Rights (TRIPS) which established rules for creating and protecting intellectual property, could be interpreted to contradict the agreements made under the CBD. Malaysia, a Contracting Party to the Convention is therefore obliged to develop under Article 6 of the Convention national strategies, plans or programmes for the conservation and sustainable use of biological resources to reflect the measures mandated under the Convention.

TRIPS is an international agreement administered by the WTO setting down minimum standards for many forms of intellectual property regulation. It was negotiated at the end of the Uruguay Round of the General Agreement on Tariffs and Trade (GATT) in 1994. The 1994 WTO's TRIPS agreement, which came into effect on 1 January 1995, introduced intellectual property law into the international trading system for the first time and remains to date the most comprehensive multilateral agreement on intellectual property. Protection and enforcement of all intellectual property rights specified under TRIPS are aimed to meet its objectives i.e. to contribute to the promotion of technological innovation and to the transfer and dissemination of technology, to the mutual advantage of producers and users of technological knowledge and in a manner conducive to social and economic welfare, and to a balance of rights and obligations. The three main features of TRIPS are standards where the Agreement sets out the minimum standards of protection to be provided by each Member in respect of each of the main areas of intellectual property covered by the TRIPS Agreement, enforcement and dispute Resolution: TRIPS makes disputes between WTO Members about the respect of the TRIPS obligations subject to the WTO's dispute settlement procedures.

\section{Protecting Traditional Knowledge to Safeguard the Indigenous Communities' Cultural Sustenance}

The pertinence of traditional knowledge can be clearly reflected from the following statement of the Director General of United Nations Educational, Scientific and Cultural Organization (UNESCO),

"The indigenous people of the world possess an immense knowledge of their environments, based on centuries of living close to nature. Living in and from the richness and variety of complex ecosystems, they have an understanding of the properties of plants and animals, the functioning of ecosystems and the techniques for using and managing them that is particular and often detailed. In rural communities in developing countries, locally occurring species are relied on for many - sometimes all - foods, medicines, fuel, building materials and other products. Equally, people's knowledge and perceptions of the environment, and their relationships with it, are often important elements of cultural identity" (Mayor, 1994).

The need to recognize, protect and enforce the rights of indigenous communities to have continued access to biological resources is quite related to the principle of sustainable management and use of biological diversity, which is pertinent not only for the continued sustenance of their culture but also to protect their knowledge, acquired over thousand of years of experimentation and experience, about the uses biological resources can be put to particularly in medicinal and pharmaceutical preparations (Latiff and Zakri, 2004). Nevertheless, commercial exploitation of traditional indigenous knowledge has become particularly aggressive over the past 20 years resulting from inequalities of bargaining power between the indigenous people and the states, which are often overlooked by WTO member states, policy makers as well as the NGOs (Davis, 2006). According to Dr Erica-Irene Daes, the former Chairperson Rapporteur on the United Nation Working Group on Indigenous Populations (1998), although global trade and investments is worth millions of dollars to trans-national corporations and states but most indigenous people are not benefiting economically of their commercialised 
knowledge. The indigenous people, as a result, are found to feel that the current approaches to traditional knowledge have not necessarily and appropriately corresponded to their views and that the existing patent and copyrights system of protection does not adequately address their collective rights (Working Group on Indigenous People, 2005).

The main concern of CBD was to prevent a further rapid loss of biodiversity, viewed not so much in terms of its adverse economic impact on the biodiversity rich developing countries but rather in terms of the availability of genetic material of vital importance to biotechnology applications in the industrialized countries (mayor, 1996). The CBD, which was signed at the United Nations Conference on Environment and Development (UNCED) in 1992, was the first international environmental convention to develop measures for the use and protection of traditional knowledge in relation to the conservation and sustainable use of biodiversity. By 2006, 188 countries had ratified the Convention and agreed to be bound by its provisions amounting to the largest number of nations to accede to any existing treaty.

The objectives of the Biodiversity Convention go far beyond what many governments and more traditional conservation organizations initially envisioned when negotiations started in 1988. In recognizing that economic and social development and poverty eradication are the first and overriding priorities of developing countries, CBD also acknowledges that the provision of new and additional financial resources and appropriate access to relevant technologies can be expected to make a substantial difference in the world's ability to address the loss of biological diversity (mayor, 1996). It also endorses the principle that states have sovereign right to exploit their own resources, that access to genetic resources "where granted, shall be on mutually agreed terms", and that providers of genetic resources should have "priority access on a fair and equitable basis . . to the results and benefits arising from biotechnologies" based on the use of their genetic resources.

\subsection{Significant Provisions under the CBD Promoting for the Protection of Traditional Knowledge}

\section{(a) Article 8 (j) - In-situ Conservation}

Each Contracting Party shall, as far as possible and as appropriate ...subject to its national legislation, respect, preserve and maintain knowledge, innovations and practices of indigenous and local communities embodying traditional lifestyles relevant for the conservation and sustainable use of biological diversity and promote their wider application with the approval and involvement of the holders of such knowledge, innovations and practices and encourage the equitable sharing of the benefits arising from the utilization of such knowledge, innovations and practices.

\section{(b) Article 10(c) - Sustainable Use of Components of Biological Diversity}

Each Contracting Party shall, as far as possible and as appropriate ... protect and encourage customary use of biological resources in accordance with traditional cultural practices that are compatible with conservation or sustainable use requirements.

The parties to the Convention set a 2010 target to negotiate an international legally-binding regime on access and benefit sharing (ABS) at the $8^{\text {th }}$ Meeting of the Conference of Parties (COP-8) on 20-31 March 2006 in Curitiba, Brazil. The ABS negotiations will address inter-governmental obligations related to genetic resources, and these will involve measures related to the rights of indigenous and local communities to control access to and derive benefits from the use of genetic resources and associated traditional knowledge.

\subsection{Sovereign Rights and $A B S$}

Article 15 of the CBD is a compromise between two opposing propositions. One group, representing mainly developed countries argued for the recognition of biodiversity resources of the world as 'common heritage of mankind' and should be freely available without exclusive claim of ownership by any country. The other group, representing mostly developing countries where most of these resources are located argued for the recognition of the sovereign rights of States over their natural resources. The text and substance of Article 15 offers a very amicable compromise in that while recognizing the sovereign rights of States to their natural resources, it imposes on these States the obligation to endeavor to create, conditions to facilitate access to genetic resources and not to impose restrictions contrary to the objectives of the Convention. Article 2 of CBD defines 'genetic resources' to include "any material of plant, animal and micro-organism communities and their non-living environment interacting as a functional unit." Access shall be on mutually agreed terms (MAT) and subject to prior informed consent (PIC). While mandating facilitation of access to genetic resources, the Convention further obligates each Contracting Party to take legislative, administrative and policy measures (LAP) for the sharing in a fair and equitable way the result of research and development and benefits arising from the commercial and other utilization of the genetic resources with the Party providing such resources. 
However, Article 15 is not a stand-alone provision. It is further buffered by the provisions of Article 8 and Article 16. In particular, Article 8(j) deserves special mention in that each Contracting Party is mandated, "subject to its national legislation, to respect, preserve and maintain knowledge, innovations and practices of indigenous and local communities embodying traditional lifestyles relevant for the conservation and sustainable use of biological diversity and promote their wider application with the approval and involvement of holders of such knowledge, innovations and practices and encourage the equitable sharing of the benefits arising from the utilization of such knowledge, innovations and practices. It must be borne in mind that the qualifying words used in Article 8 are, "shall, as far as possible and as appropriate" and similar qualifying words in para (j) "subject to its national legislation" appear to allow Contracting Parties to offer excuses for non compliance on the basis of perceived inappropriateness and unsuitability. Be that as it may, the full dimension of Article 15 provisions read together with Article 8(j) offer a regime of ABS with proper respect being given to the involvement of owners of traditional knowledge in both the promotion of wider application of such knowledge and the equitable sharing of benefits derived from use of such knowledge. It is obvious that the full benefits of Article 15 can only be realized within a framework of LAP measures that address the main components of ABS, namely:

Establishing and identifying the authorities responsible for granting prior informed consent.

Establishing an appropriate benefit sharing arrangements and procedures.

Inventory of existing traditional knowledge and a register of owners of such knowledge from among the indigenous population.

Apart from the limited pioneering experience of a handful of countries in establishing the ABS regimes, ABS remains essentially an uncharted territory. In an attempt to provide a guiding mechanism which could act as a precursor to a more comprehensive ABS mechanism, the Bonn Guidelines on Access to Genetic Resources and Fair and Equitable Sharing of the Benefits Arising out of their Utilization were formulated and adopted in 2002 by member countries. While work on more appropriate regime on ABS was in progress in many member countries, concerns have been raised in many quarters, mainly diversity rich developing nations, that the full realization of the objectives of Article 15 may effectively be undermined by the Agreement on Trade Related Aspects of Intellectual Property Rights (TRIPS) of the World Trade Organisation. It has been argued that the CBD and WTO/TRIPS "are in conflict with one another" (Suman Sahai, 2003). The debates on this perceived conflict center primarily on the lack of recognition of the objectives of the CBD by some members and that they are encouraged and emboldened in this respect by the text of Article 27.3(b) of the TRIPS agreement itself which appear to give precedence to private right over public rights and allows the recognition of patents and other IPRs using genetic resources and traditional knowledge without prior informed consent and benefit sharing and without the due recognition given to owners of such traditional knowledge. Article 27.3(b) of TRIPS reads:

Patentable Subject Matter

3). Members may also exclude from patentability:

(b) plants and animal other than microorganism, and essentially biological processes for the production of plants or animals other than non-biological and microbiological processes. However, members shall provide for the protection of plant varieties either by patents or by an effective .... Generis system or by any combination thereof. The provisions of this paragraph shall be reviewed four years after the date of entry into force of the WTO Agreement.

Owing to continued tussle between the developed and developing nations, the review of Article 27.3(h) mandated by the Article itself did not take place in 1999 but started a year later in 2000. However, it was in December 2001 at the DOHA Ministerial of the WTO that a far reaching dimension of the review was agreed in the form of para 19 of the DOHA Declaration. Member countries made the following decision:

"We instruct the Council of TRIPS, in pursuing its work programme including under the review of Article 27.3(b), the review of the implementation of the TRIPS Agreement under Article 71.1 and the work foreseen pursuant to paragraph 12 of this declaration, to examine, inter alia, the relationship between the TRIPS Agreement and the Convention of Biological Diversity, the protection of traditional knowledge and forklore, and other relevant new developments raised by members pursuant to Article 71.1. In undertaking this work, the TRIPS Council shall be guided by the objectives and principles set out in Article 7 and 8 of the TRIPS Agreement and shall take fully into account the development dimension."

However, despite several negotiations under this mandate views continue to show a sharp divergence oscillating towards two extreme positions. On one of the extreme is the African group who has taken the position against 
the patent on life forms and has urged that Article 27.3(b) should be revised to prohibit patents on plants, microorganism and essentially biological processes for the production of plants and animals, including non-biological processes. On the other extreme is a group of developed countries led by United States of America, Australia and Japan, supported by Korea and Singapore which believe that there is no conflict between TRIPS and CBD and that the exceptions to patentability in Article 27.3(b) were unnecessary. The group is also of the view that in the interest of scientific advancement, transparency and technology transfer, it is necessary to provide patents on plants and animals. The group argued against the use of TRIPS to enforce ABS.

In between these two extremes are the groups of developing countries led by Brazil and India and including Bolivia, Columbia, Cuba, Dominican Republic, Equador, Peru and Thailand and the European Union group. The India-led group submitted two proposals; the first calling for "a mandatory disclosure of the source of origin of the genetic resources and associated TK". In later proposal the group urged for a patent application based on genetic resources and TK to show evidence of benefit sharing with country of origin and non compliance should result in the patent application being stopped or withdrawn. Moreover the group demanded that where non-compliance is discovered after the granting of the patent, the patent should be revoked.

Representing a more conciliatory stand is the EU group who agrees with the inclusion of the disclosure requirement in TRIPS but argues that failure to disclose, prior to or after the grant of patent shall not affect the grant of patent or the validity of patent already granted. The two main diverging views remain poles apart to this day, although there have been numerous attempts to negotiate mutually acceptable compromises. Significantly South Asia Watch on Trade, Economic \& Environment in its Policy Brief has offered several conciliatory options, particularly to allow for patents on life forms of genetically modified plants, animals, organisms and associated non-biological processes and such patent to cover real inventions and not mere discoveries and the right of Member States to reject patent on life forms on grounds of ethical, religions, environmental and development concerns (SAWTEE, 2007).

The International Chamber of Commerce (ICC, 2004) meanwhile, views the making of disclosure requirement a condition of patentability as a disturbing development because it tends to turn it into an enforcement tool rather than a tool to encourage access to innovation. It also raises the logistic problems of identifying with reasonable degree of legal certainty the holders of TK. With due respect, if disclosure requirement, once included in the TRIPS Agreement is perceived as a tool of enforcement, the opposite is equally true: its absence without TRIPS will allow TRIPS to be used as a tool to avoid the meaningful implementation of the objectives of CBD, in particular ABS and PIC.

Protecting the traditional knowledge of local communities and the interests of holders of such knowledge are as important as protecting the intellectual property rights. Protection of traditional knowledge according to the spirit of the CBD is a double edged-sword: while the knowledge's holders or originators are benefited, the broader public interest will also be served under ABS. The profits from the exploitation of traditional knowledge should be shared by local communities. Likewise, their contribution to the advancements in science and technology through the knowledge should also be acknowledged (Paterson and Karjala, 2003).

The World Intellectual Property Organization (WIPO), which was mandated to study the relationship between intellectual property rights, biodiversity and traditional knowledge through Paragraph 19 of the 2001 Doha Declaration, established the Intergovernmental Committee on Intellectual Property and Genetic Resources, Traditional Knowledge and Folklore (IGC-GRTKF). This committee comprises of different nations, organizations, and indigenous and local communities to address the policy/legal issues with traditional knowledge protectionism. According to Hansen (2002), providing protection of traditional knowledge of local communities by reforming the domestic and global intellectual property regime is vital due to two pressing reasons:

1) The importance of biological resources for the welfare of many communities, which according to World Health Organisation, up to $80 \%$ of the world population relies on medicinal plants for their primary health; and

2) The conflicting situations where TRIPS continuing efforts to strengthen the mechanism for private ownership of the same resources, which the $\mathrm{CBD}$ is trying to protect as communal rights.

Implementing the provisions of Article 8(j) and Article 10(c) of the CBD and allowing ABS to be legally practiced would first require that international intellectual property agreements be revised to accommodate them. Since many countries are both signatories to both the CBD and TRIPS, by implementing the TRIPS Agreement, protections offered under Article $8(\mathrm{j})$ of the $\mathrm{CBD}$ for protecting local community rights to biological resources and intellectual property are undermined (Hansen, 2002). TRIPS do not recognise the communal nature and 
cultural laws governing traditional knowledge. There were also concerns over the territorial rights and traditional resource rights of indigenous peoples and local communities as well as the misappropriation and misuse of their knowledge and cultural heritage. They have defied, inter alia, the patenting of traditional uses of medicinal plants.

Over the concern that developed countries were insisting on an overly narrow reading of TRIPS, developing countries initiated a round of talks in 2001 resulting in the Doha Declaration, which clarifies the scope of TRIPS. The Doha Declaration says that work in the TRIPS Council on these reviews or any other implementation issue, guided by the objectives and principles of the TRIPS Agreement (Article 7 and Article 8 respectively), should also look at the relationship between the TRIPS Agreement and the CBD, the protection of traditional knowledge and folklore; and other relevant new developments that member governments raise in the review of the TRIPS Agreement.

Paragraph 19 of the 2001 Doha Declaration has asked for the review of Article 27.3(b) of TRIPS, which deals with patentability or non-patentability of plant and animal inventions, and the protection of plant varieties (WTO, 2003). The provisions of Article 27.3(b) requires member countries to grant patent protections in these areas, which were not previously covered under the intellectual property protections: a member country refuses to do so must implement an alternative - domestic form of the intellectual property protection for these resources, which are known as the sui generis intellectual property systems (Hansen, 2002). TRIPS Council was also mandated to look at the relationship between the TRIPS Agreement and the UN Convention on Biological Diversity, the protection of traditional knowledge and folklore.

According to Davies (2006), among a number of concerns with TRIPS, the indigenous people are particularly concerned with the effectiveness of Article 8 of TRIPS Agreement as well as its possible manipulation to the detriment of the development of sui generis intellectual property systems. Article 8 vaguely reads,

Members may ....adopt measures necessary to protect public health and nutrition, to promote the public interest in sectors of vital importance to their socio-economic and technological development, provided that such measures are consistent with the provisions of this Agreement.

Theoretically, TRIPS through sui generis intellectual property systems allows member countries to develop and implement domestic laws and mechanisms to recognise and protect traditional knowledge and biological resources while still involved in the global intellectual property regime: many countries, who have proposed or partially implemented models for these sui generis systems, recognise undocumented oral and traditional uses as sufficient evidence of prior art to preclude patenting of that particular knowledge in their countries (Hansen, 2002). However, the practice in the U.S, which does not recognise traditional uses outside its own jurisdiction nor any undocumented knowledge, may defeat the intention of the countries interested in implementing sui generis systems to protect their resources domestically or globally. This is because the filing of one international patent application under WIPO's Patent Cooperation Treaty, the applicant can simultaneously seek proprietary rights in over 100 hundred countries across the globe: many developing countries, devoid of record or knowledge of their own traditional knowledge as well a sui generis system in position may unwittingly grant patents. This "innocent" act may cost these countries the proprietary rights and control over their own local traditional knowledge and genetic resources.

Sreenivasan and Christie admit this frightening prospect by stating that while the southern countries are favoured in terms of biodiversity, most of the agro and pharmaceutical corporations are based in the North: in their quest for knowledge of and access to genetic resources crucial to their product development, many extend the use of intellectual property rights, facilitated by TRIPS, into the realm of living things abundant in the South (Sreenivasan \& Christie, 2002). They both abhor TRIPS on the sense that it is antithetical to liberalised trade because of its nature of facilitating monopoly and continue to note that,

"TRIPS agreement is based on IPR standards in industrialised countries. Governed by WTO, it has many components and many implications for development and poverty eradication in the South."

In order to properly protect traditional knowledge and to employ global mechanisms for equitable benefit sharing, as envisioned by COP- 8 , it is necessary to reform both the domestic and global intellectual property regimes. This fact was conceded by WIPO (2001) that the intellectual property system is in direct conflict with traditional practices and lifestyles by stating that,

"Traditional knowledge holders are situated between their own customary regimes and the formal intellectual property system administered by governments and inter-governmental organisations such as 
WIPO. ...The intellectual property needs of traditional knowledge holders receive their complexity, diversity and relevance from multiple intersections of these factors."

The Indigenous Groups in Attendance (2004) proposed 11 recommendations to the United Nation Conference on Trade and Development (UNCTAD) for the protection of traditional knowledge. The recommendations to be considered by UNCTAD are inter alia for priority to be given to the strengthening of existing customary laws and value systems of indigenous peoples in the protection of traditional knowledge, for the banning of life forms patenting because of its invasive nature to the values and livelihoods of indigenous and traditional peoples, and for the establishment of An Indigenous Peoples Working Group (IPWG) on traditional knowledge for the purpose of developing mechanisms for the protection and enhancement of traditional knowledge systems and to take the lead role in the development of mechanisms for the protection of traditional knowledge.

The international standards relating to the protection of traditional knowledge emerging out of the WIPO and the CBD are:

1). The development of any policies, laws or rules regarding traditional knowledge and associated resources must involve the full and effective participation of indigenous and local communities;

2). Access to traditional knowledge and resources (particularly genetic resources) can only be obtained through the free, prior informed consent (FPIC) of indigenous and local communities; and

3). Indigenous and local communities have the right to determine the form of benefit sharing, and use by others can only proceed on the basis of mutually agreeable terms between the custodians or holders of knowledge and resources and external parties.

\section{Conclusion}

It is obvious that recognizing, protecting and ensuring the rightful place of traditional knowledge within the broader framework of sustainable use and conservation of biological diversity requires a total review of existing legislation pertaining to the rights of indigenous people beyond formal declarations (Shaik \& Wan Izatul, 2008). Since indigenous communities have come to be appreciated as repositories of not only of knowledge but also of biological diversity itself, traditional knowledge of indigenous and local communities must always be protected by domestic laws of the member state of TRIPS and CBD.

Although Malaysia has amply shown her commitment towards environmental issue and the conservation of biological resources both through effective domestic legislative, administrative and policy measures as well as active involvement in and speedy ratification of international agreements and protocols on environmental biodiversity and safe and sustainable use of resources, there are still many policy and legislative aspects of safe and sustainable use of resources that require urgent revisit, especially having in mind Malaysia's obligation to comply with CBD.

As of now, there is no single unified and comprehensive federal legislation to deal with the management, safe and sustainable use of biological resources. This is quite understandable in view of the fact that resources are under the jurisdiction of individual states. This notwithstanding there are provisions in the Federal Constitution to enable such a broad comprehensive federal law on biodiversity to be enacted. Such a law may provide for the much needed central direction and central authority to meet the many demands of the CBD. However, with or without the comprehensive federal legislation, there is indeed a dire need to immediate formulate a suitable ABS mechanism, incorporating explicit recognition and participation of owners of traditional knowledge.

\section{References}

Alaska Native Science Commission. (2006). What is Traditional Knowledge? Retrieved August 18, 2009, from http://www.nativescience.org/html/traditional_knowledge.html

CBD. Outcomes of Article 8 (j). Retrieved August 26, 2009, from http://www.cbd.int/traditional/outcomes.shtml

Cunningham, W. P., \& Cunningham, M. A. (2007). Environmental Science Global Concern. Mc Graw Hill: New York. In Sulaiman, S.S., \& Md. Khalid, R. (Eds.), Biodiversity Conservation in Taman Negara-Legal and Planning Issues. International Conference on Environmental Conference on Environmental Research and Technology (2008), Penang.

Daes, Erica-Irène, WIPO. Opening Address at the Rountable on Intellectual Property and Indigenous People, Geneva On 23 July 1998. 
Davis, Megan. (2006). International Trade, the World Trade Organisation and the Human Rights of Indigenous People. 8 Balayi: Culture, Law and Colonialism.

FRIM. Status of Biological Diversity Management in Malaysia. Retrieved October 15, 2008, from http://www.frim.gov.my/CHM/IFBiologicalDiversityStatus.html

Hansen, Stephen A. (2002). Intellectual Property and Traditional Ecological Knowledge: Institutionally Globalized Biopiracy? Professional Ethics Report, XV(3), Summer.

How Useful are Standards? Feng Shui Times - June 2003. Retrieved August 18, 2009, from http://qi-whiz.com/node/997

Intergovernmental Committee on Intellectual Property and Genetic Resources. (2001). Traditional Knowledge and Folklore: First Session, WIPO/GRTKF/IC/1/12.

Mayor, Federico. (1994). Director General of United Nations Educational, Scientific and Cultural Organization (UNESCO). $\quad$ Retrieved August $18, \quad 2009, \quad$ from http://www.unesco.org/education/tlsf/TLSF/theme_c/mod11/uncom11t01bod.htm

Mayor, Federico. (1996). Director General of United Nations Educational, Scientific and Cultural Organization (UNESCO). Address to the Asian Regional Workshop on Ecotechnology and Shaping the Future at the M.S. Swaminathan Research Foundation, Madras, 4 February.

Nijar, G.S. (1995). AH Zaki (Ed.). Prospects in Biodiversity Prospecting' Universiti Kebangsaan Malaysia, 225-265.

Nina L. Etkin. (1998). Indigenous Patterns of Conserving Biodiversity: Pharmacological Implication. Journal of Ethno Pharmacology, 63(3), December, 233-245. http://dx.doi.org/10.1016/S0378-8741(98)00102-0

R Paterson, \& D Karjala. (2003). Looking Beyond Intellectual Property in Resolving Protection of the Intangible Cultural Heritage of Indigenous Peoples, 11. Cardozo Journal of International Law and Comparative Law, 633.

Report of the Working Group on Indigenous Populations on its 23rd Session, E/CN.4/Sub.2/2005/26 (2005).

S. Sothi Rachagan. Sustainable Forest Management in Malaysia - Guidelines for Conflict Resolution.

Secretariat of the Permanent Forum on Indigenous Issues. Indigenous People and the International and Domestic Protection of Traditional Knowledge, E/CN.4?Sub.2/AC.4/2005/CRP.4 (2005).

Secretary General of the Ministry of Natural Resources speech at the International Conference on Biodiversity: Science and Governance at UNESCO Headquarters, Paris on January 24 to 28 2005. Malaysia is estimated to have 15,000 plants species, 4,000 fish species and 150,000 species of insects and invertebrates.

Shaik Mohd Noor Alam S.M. Hussain, \& Wan Izatul Asma Wan Talaat. (2008). Law and Policy on Biodiversity in Malaysia. Biodiversity and Biotechnology Symposium 2008, Hilton Kuching, Sarawak, Malaysia on 19-21 November 2008.

Sreenivasan, G., \& Christie J. (2002, March). Intellectual Property, Biodiversity, and the Rights of the Poor. Canadian Council for International Co-operation: Trade and Poverty Series.

Srividya Ragavan. (2001). Protection of Traditional Knowledge. MINNESOTA INTELLECTUAL PROPERTY $L A W$ REVIEW, 2(2).

Twarog, Sophia. Preserving, Protecting and Promoting Traditional Knowledge: National Actions and International Dimensions. In Twarog, Sophia, \& Kapoor, Promila (Eds), Protecting and Promoting Traditional Knowledge: Systems, National Experiences and International Dimensions (2004). United Nations: New York \& Geneva.

WTO. (2009). Overview: The TRIPS Agreement. Retrieved September 1, 2009, http://www.wto.org/english/tratope/tripse/intel2e.htm

WTO. (2003). Review of Article 27.3(B) of the Trips Agreement, and the Relationship between the Trips Agreement and the Convention on Biological Diversity (CBD) and the Protection of Traditional Knowledge and Folklore. 